\title{
Performance Analysis of FSR, LAR and ZRP Routing Protocols in MANET
}

\author{
I. Sumaiya Thaseen \\ School of Information Technology and Engineering, \\ VIT University, \\ Vellore, India
}

\author{
K. Santhi \\ School of Information Technology and \\ Engineering, \\ VIT University, Vellore, India
}

\begin{abstract}
Mobile Ad Hoc Network (MANET) is a collection of mobile nodes communicating with each other without any infrastructure in a multi hop fashion. In a MANET, nodes are moving arbitrarily, so the network may experience rapid and randomly topology changes. This paper presents performance comparison of three dissimilar routing protocols i.e. Fisheye State Routing (FSR), Location aided Routing (LAR) and Zone Routing Protocol (ZRP) with respect to variable pause times. This research paper provides an outline of these protocols by presenting their functionality, benefits, characteristics, limitations and analysis. Performance of FSR, LAR and ZRP is evaluated considering the parameters average end-toend delay, packet delivery ratio and throughput using network simulator Qualnet 5.0.2. The simulation shows that LAR protocol exhibits good performance in comparison to other routing protocols.
\end{abstract}

Keywords- FSR, MANET, LSR, ZRP

\section{INTRODUCTION}

A Mobile Ad-Hoc Network (MANET) consists of self governing mobile nodes communicating in a decentralized manner. The goal of routing protocol is to determine paths with reduced overhead and also faster reconfiguration when a broken link is identified [5]. Every node has the responsibility to determine the best route to its destination. A lot of research study is performed on various routing protocols but this paper presents a comparison of FSR, LAR and ZRP operating based on scope and zones. These techniques identify the route to a destination efficiently thereby achieving higher throughput with reduced delay. No such analysis has been done comparing the above said protocols using the commonality between them ie.zones.

\section{ROUTING PROTOCOLS}

Routing protocols are classified into three major categories: Proactive, Reactive and Hybrid. Proactive also called table driven forwards the packet to already known route by continuously evaluating the routes within the network. Each node maintains the routing information and updates it consistently. A reactive protocol also known as on demand performs the routing process only when required. A route discovery has to be initiated by the node when no route is found. Hybrid protocols have the benefits of proactive and reactive protocols.

\section{FISHEYE STATE ROUTING}

Fisheye State Routing (FSR) [11] is based on proactive routing. Klein \& Stevens proposed "Fisheye" technology to reduce graphics and image data. The characteristic of "Fisheye" is that the information across the focal length can be clearly caught, while the information beyond the focal length is vague. FSR routing protocol makes use of this feature of fisheye vision to broadcast routing update information with different frequencies thereby reducing the routing overhead and decreasing the flood cost of updating information. FSR routing protocol distributes information using the "Fisheye" technology, and does not broadcast routing update information in the whole network, thus reducing the controlling overhead caused by the router updating of information; while linkstate routing protocol will cause flooding of the routers updating information in the whole network, when the router at the node changes. FSR is an enhancement of GSR. GSR uses a considerable amount of bandwidth as the size of update messages is very large.
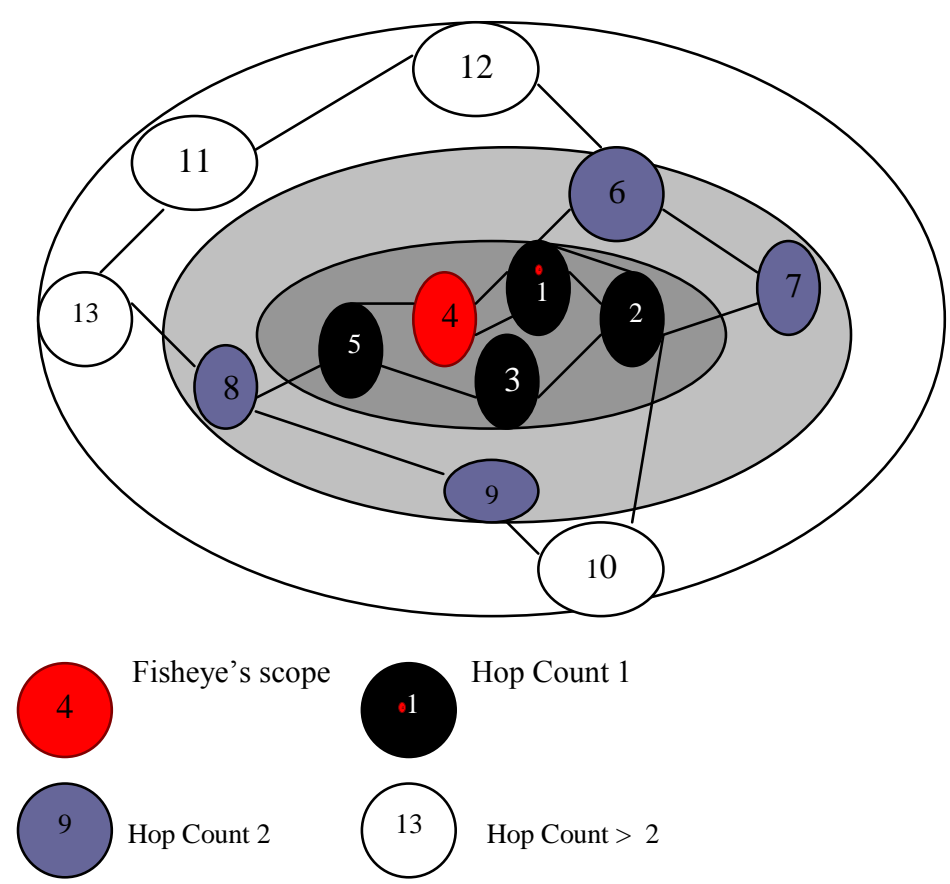

Fig 1 : Scope of Fisheye

The above figure denotes the fisheye's scope specified by the center red node. Number of hops required to arrive at a specific node is defined as scope.

In FSR [8], information about nearer nodes is exchanged more often than for the farther nodes as the update message size is less. The center node maintains the updated information regarding the nodes located in the inner circle. As a result when the node is farther away, 
the correctness of information about the node decreases. Advantage of FSR is it is appropriate for larger networks thereby controlling overhead. FSR is simple because it maintains updated shortest routes. The disadvantage of FSR is limited scalability. The other disadvantages are processing overhead and the storage complexity. FSR doesn't provide security compared to other protocols.

\section{LOCATION AIDED ROUTING}

Location aided routing (LAR) is an improvement to flooding algorithms to reduce overhead due to flooding. The aim of LAR is to send the route requests only to a particular area expected to include the destination thereby decreasing overhead.

LAR uses two zones: Request zone and Expected zone. Expected zone includes the region where the destination is located. The request zone can be expanded covering entire network on unsuccessful path discoveries. The route request flooding is restricted to a request zone during route discovery procedure containing the location of the sender node and expected zone. Hence there should be a careful balance between reduced overhead and increased latency

\section{1 LAR Schemes}

\subsubsection{Expected zone and Request Zone}

Node $\mathrm{S}$ is the source and Node $\mathrm{D}$ is the destination. Node $\mathrm{S}$ expects to have node $\mathrm{D}$ in the region called as expected zone for the destination. Node $\mathrm{S}$ considers the speed with which node $\mathrm{D}$ travels to determine the expected zone D. Circular expected zone is decreased to a semi-circle if source node identifies destination is moving towards north. Source node identifies a Request Zone similar to figure 3 (a).

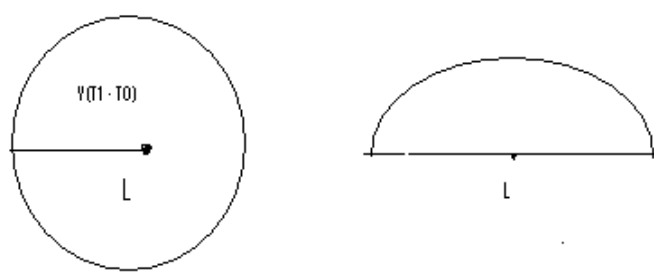

Figure 2: Expected zone and semi zone

The advantage of Location Aided Routing Protocol is it reduces routing overhead of the ad-hoc network by using location information. Complexity of protocol is reduced assuming that each node recognizes position accurately. Limitations of this protocol is every host requires a GPS device.

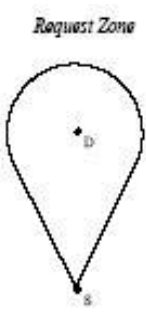

(a)

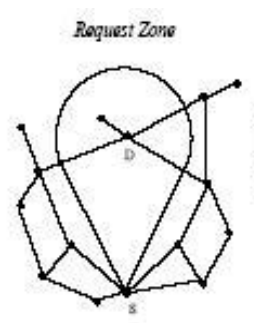

(b)

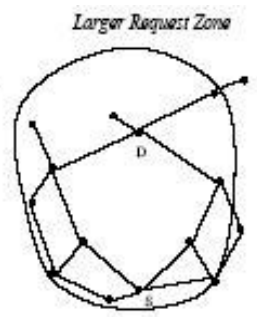

(c)

\section{ZONE ROUTING PROTOCOL}

Zone Routing Protocol (ZRP) [6] combines the benefits of proactive discovery inside node's limited neighborhood (Intra Zone Routing Protocol (IARP)) [3], and also uses a reactive protocol for interaction among neighborhoods. The Broadcast Resolution Protocol (BRP) is used to forward route request. ZRP partitions the complete network in many zones. This protocol is classified as a flat protocol due to overlapping of zones. As a result network congestion can be reduced and optimal routes can be detected. [10].

Peripheral nodes are nodes containing minimum distance from the node equal to the zone radius. IARP requires Neighbor Discovery Protocol. Hello messages identify link failures and ensure that neighbors are present. IERP is invoked if IARP is unable to locate the destination, i.e., the destination is outside node's zone. Control traffic can be reduced to a minimum with correct zone size. ZRP achieves better performance. IARP [3] is adapted as the proactive component and IERP is adapted as the reactive component of ZRP. Hence the complexity of ZRP is high.

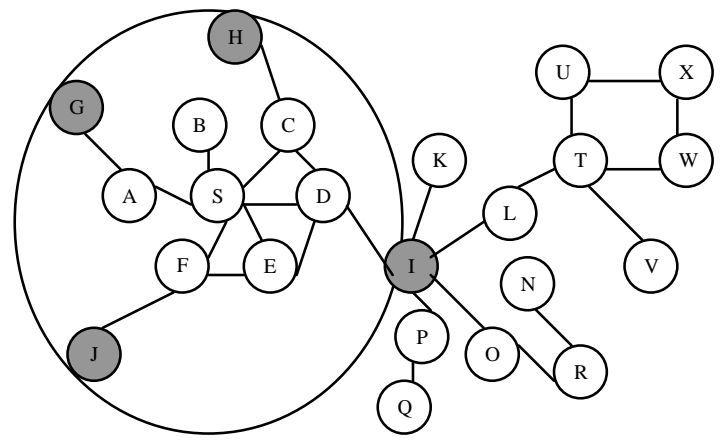

Figure 4: ZRP

This example shows the node $\mathrm{S}$ which is the source sends packet to destination i.e. node $X$. This diagram has zone radius $r=2$. To check whether destination is within its zone checking by node uses the routing table offered by IARP because if not found then route request is issued by IERP. Request is broadcast to peripheral nodes represented gray in fig 4 .

The advantage of this protocol is there is a significant reduction in communication overhead and delay when compared with proactive approaches. FSR performs faster route discovery. The disadvantage of ZRP is when the zone radius is less it performs in a proactive manner whereas for reduced values it acts in a reactive manner.

Figure 3 :Request zone 


\section{CHARACTERISITIC SUMMARY OF ZRP,LAR AND FSR}

Table 1 : Comparison of three routing protocols

\begin{tabular}{|c|c|c|c|}
\hline Protocol & ZRP & FSR & LAR \\
\hline Category & Hybrid & $\begin{array}{l}\text { Table } \\
\text { Driven }\end{array}$ & Reactive \\
\hline Metric & $\begin{array}{c}\text { Shortest } \\
\text { Path }\end{array}$ & $\begin{array}{l}\text { Scope } \\
\text { range }\end{array}$ & $\begin{array}{c}\text { Shortest } \\
\text { Path }\end{array}$ \\
\hline Route Repository & $\begin{array}{c}\text { Interzone, } \\
\text { Intrazone } \\
\text { tables }\end{array}$ & $\begin{array}{c}\text { Routing } \\
\text { tables }\end{array}$ & $\begin{array}{l}\text { Request } \\
\text { Zone\& } \\
\text { Expected } \\
\text { Zone }\end{array}$ \\
\hline $\begin{array}{l}\text { Multicast } \\
\text { capability }\end{array}$ & No & No & No \\
\hline Route Recovery & $\begin{array}{c}\text { Start repair } \\
\text { at failure } \\
\text { point }\end{array}$ & $\begin{array}{l}\text { Notify } \\
\text { Source }\end{array}$ & $\begin{array}{l}\text { Notify } \\
\text { Source }\end{array}$ \\
\hline Multiple paths & Yes & Yes & Yes \\
\hline $\begin{array}{c}\text { Communication } \\
\text { Overhead }\end{array}$ & Medium & Low & Medium \\
\hline $\begin{array}{l}\text { Hello message } \\
\text { Requirement }\end{array}$ & Yes & No & No \\
\hline $\begin{array}{c}\text { Storage } \\
\text { Complexity }\end{array}$ & $\left.\begin{array}{c}\mathrm{O}(\mathrm{M}+\mathrm{B}+(\mathrm{D} \\
1\end{array}\right)$ & $\mathrm{O}\left(\mathrm{N}^{*} \mathrm{~A}\right)$ & $\mathrm{O}(\mathrm{N})$ \\
\hline \multicolumn{4}{|c|}{$\begin{array}{c}\text { d: Network Diameter ; } \mathrm{D}^{1}: \text { The Number of maximum } \\
\text { desired destination ; N : Number of Nodes in the Network; } \\
\mathrm{M} \text { : Average Number of Nodes in a zone; B : The average } \\
\text { gateway nodes of a zone; A: Average Number of } \\
\text { Neighboring Nodes }\end{array}$} \\
\hline
\end{tabular}

\section{SIMULATION SETUP}

The Qualnet 5.0.2 simulator is used for performance comparison of FSR, LAR and ZRP. The animated simulation is shown in figure 5. The IEEE 802.11 [9] is used as the Medium Access Control layer protocol for wireless Local Area Networks. The 50 nodes are placed uniformly over the region of $1500 \mathrm{mx} 1500 \mathrm{~m}$. In the scenario UDP (User Datagram Protocol) connection is used and over it data traffic of Constant bit rate (CBR) is applied between source and destination. The random waypoint model of mobility model is used in a rectangular field. The multiple CBR application is applied over different source and destination nodes.

\subsection{Metrics:}

\section{1. 1. Throughput}

Figure 8 shows the average rate of successful message delivery over a communication channel. The throughput is measured in bits per second (bit/s or bps), and rarely in packets per second or packets per time slot

\subsubsection{End-to-End delay}

Figure 6 shows End-to-end delay: This delay refers to the time required for a packet to be sent across a network from source to destination.

\subsubsection{Packet Delivery Ration (PDR)}

Figure 7 shows Packet Delivery Ratio: PDR is defined as the ratio between the total number of packets sent by the source and received by the destination.

Table 2 : Simulation Parameters

\begin{tabular}{|c|c|}
\hline Parameters & Value \\
\hline Area & $1500 \mathrm{~m} \mathrm{X} \mathrm{1500} \mathrm{m}$ \\
\hline Channel Frequency & $2.4 \mathrm{GHz}$ \\
\hline Data rate & $2 \mathrm{Mbps}$ \\
\hline Path Loss Model & Two Ray Model \\
\hline Mobility Model & Random- way point \\
\hline Packet Size & 512 bytes \\
\hline Physical Layer \\
Radio Type & IEEE $802.11 \mathrm{~b}$ \\
\hline MAC Protocol & \\
\hline Antenna Model & IEEE 802.11 \\
\hline
\end{tabular}

\section{RESULTS AND DISCUSSIONS}

The Qualnet 5.0.2 network simulator has been used to analyze the parametric performance of Zone Routing Protocol (ZRP), Fisheye State Routing Protocol (FSR) and Location Aided Routing (LAR). The metric based analysis is shown in figure 5 to figure 8 .

Throughput: The throughput is analyzed with varying CBR data traffic. According to our simulation results better performance is shown by FSR at high mobility but in other cases it has lower throughput. Throughput of FSR, LAR and ZRP is increasing as the network size is increasing but FSR performs well in large sized networks. Throughput of ZRP is well and it's nearer for small and large network but for large sized network it is decreasing. It is found that FSR performs better than ZRP because of reduced routing traffic overhead in route discovery and multi level scope technique. Due to Zone method, ZRP has not performed better than FSR.

End-to-End Delay: From the graphs we see that the average packet delay increases with number of nodes while routing protocols try to find valid route to the destination. Besides the actual delivery of data packets, the delay time is also affected by route discovery, which is the first step to begin a communication session .In this analysis it is observed as expected the delays are more for ZRP in comparison to FSR. Delays are incurred by ZRP'S IARP and IERP methods. The end-to-end delay of FSR is less because it has reduced routing overhead and queuing delay. Also LAR has variable delay with respect to node density.

Packet Delivery Ratio: FSR performs better than ZRP except at nodes 25, 50, 75 due to low overheads. The ZRP performs better at these nodes as low mobility nodes are in their source zone and also due to proactive maintenance of routing zones. There is an 
improvement in PDR for ZRP due to implementation of hybrid protocol. In comparison to ZRP and LAR, LAR is better due to the usage of request zone and expected zone and thereby reduced traffic overhead.

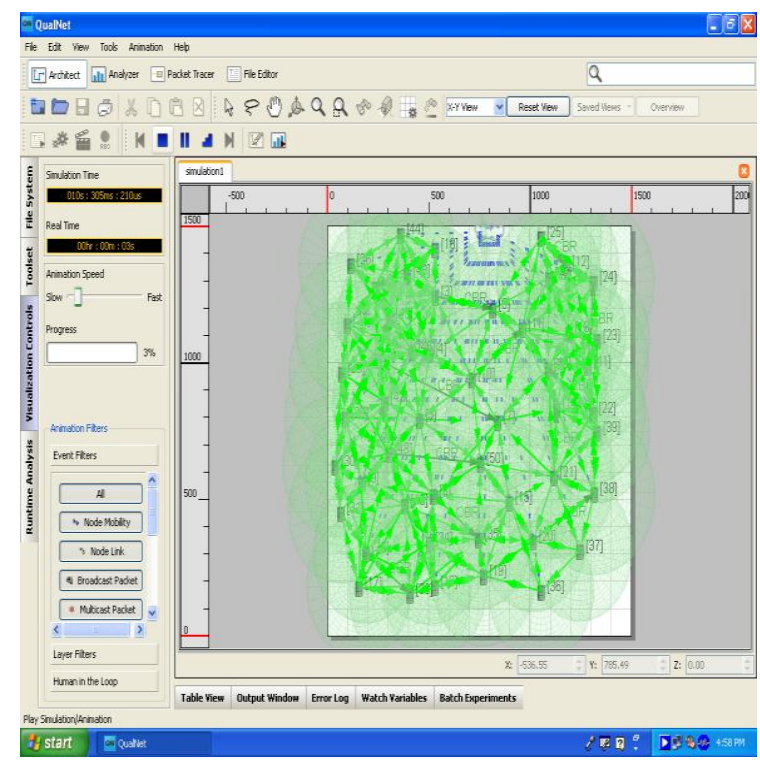

Figure 5: Snapshot of Simulation

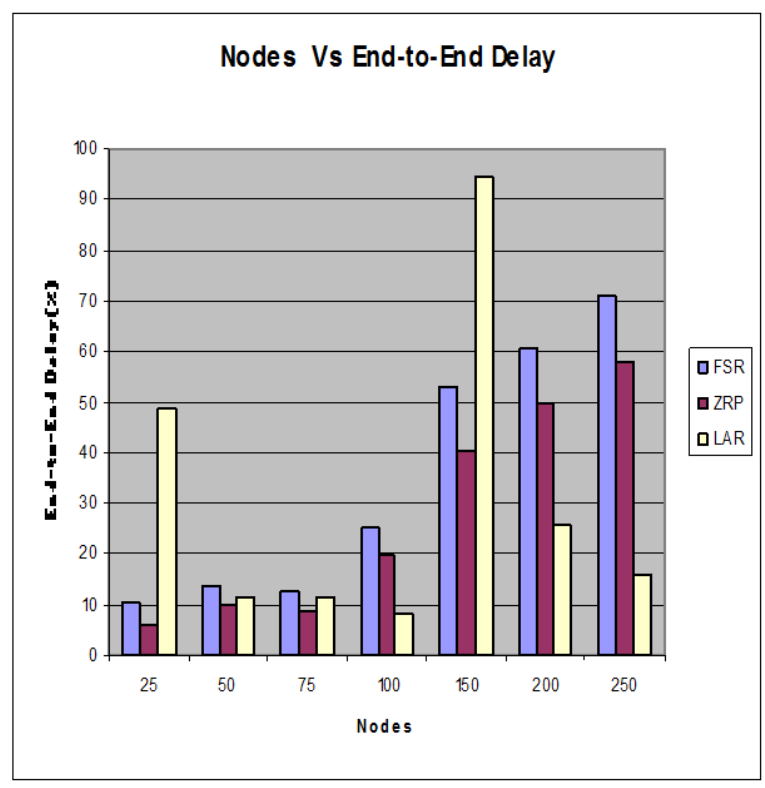

Figure 6 : End- to-End Delay Vs Node ID

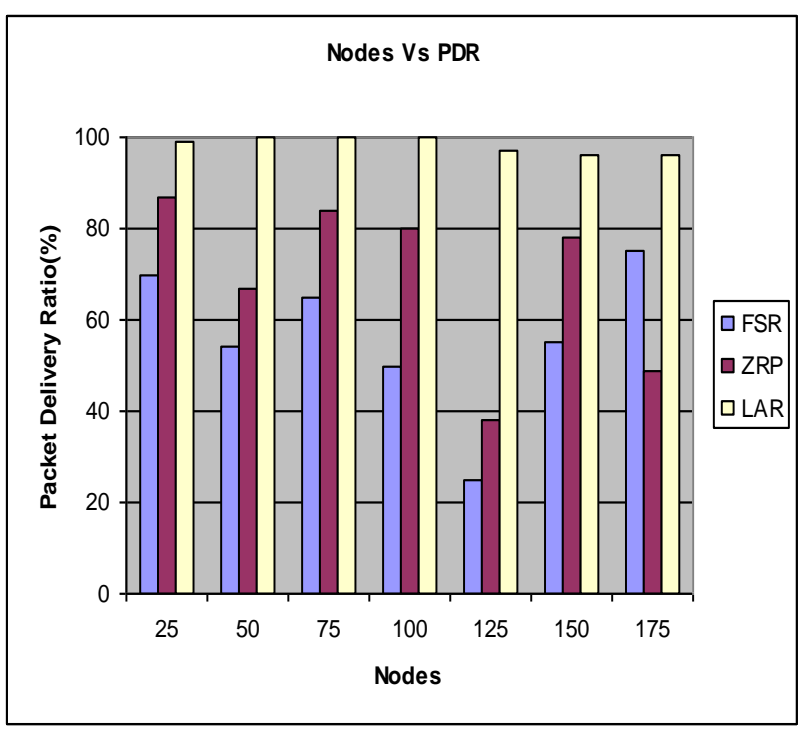

Figure 7: Packet Delivery Ratio Vs Node ID

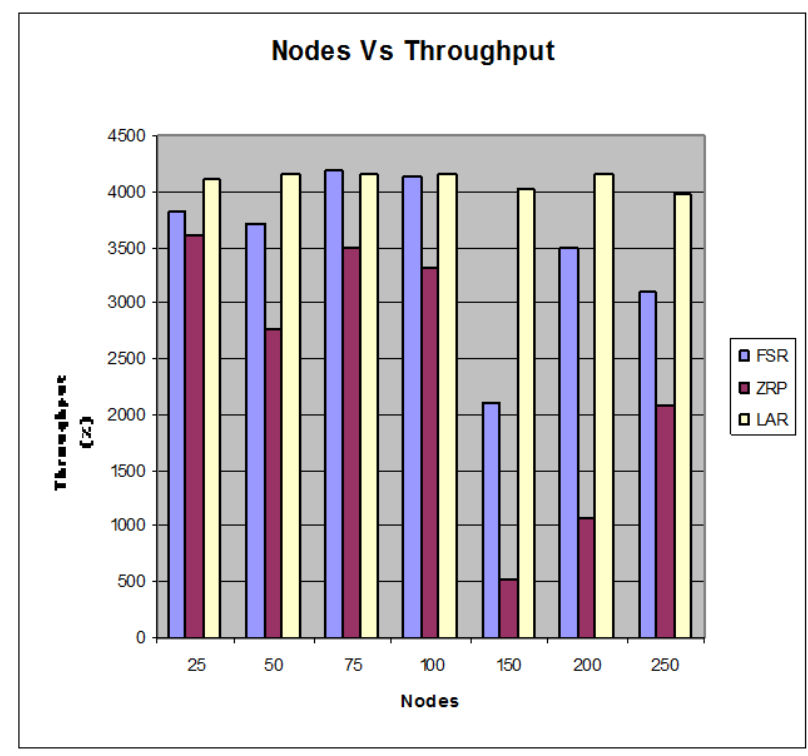

Figure 8: Throughput Vs Node ID

\section{CONCLUSION}

It is observed in the analysis that LAR outperforms ZRP and FSR in general for all the scenarios due to reduced overhead and multi level scope technique. FSR is highly suitable for dynamically changing network topology and thus the throughput is high with high mobility of nodes whereas throughput of LAR is higher at start but it falls as the node density increases. FSR reduces the size of tables which is exchanged by maintaining less accurate information about nodes farther away. In LAR, route requests packets propagate in the request zone only. ZRP is suitable for low mobility and hence it experiences very high average end-to-end delay with high mobility. ZRP maintains strong network connectivity inside the routing zones while determining remote route faster than flooding.

The simulation study has been conducted using network simulator Qualnet 5.0.2 for the performance comparison of FSR, LAR and ZRP protocols. There is an improvement in LAR when compared to other protocols. Hence we can conclude that LAR is best when compared to all other routing protocols. 


\section{REFERENCES}

[1] C. S. R. Murthy, B. S. Manoj, "Ad Hoc Wireless Networks: Architecture and Protocols", ch. Routing Protocols for Ad Hoc Wireless Networks, pp. 299-364.

[2] Kuncha Sahadevaiah,Oruganti Bala Venkata Ramanaiah,” An Empirical Examination of Routing Protocols in Mobile Ad Hoc Networks" Int. J. Communications, Network and System Sciences, June 2010, 3, 511-522

[3]Haas, Z.J., Pearlman, M.R. and Samar, P., "Intrazone Routing Protocol (IARP)," IETF Internet Draft, draft-ietfmanet-iarp02.txt, July 2002.

[4] Haas, Z.J., Pearlman, M.R. and Samar, P., "Interzone Routing Protocol (IERP)," IETF Internet Draft, draft-ietfmanet- ierp02.txt, July 2002.

[5] C.K. Toh, "Ad Hoc Mobile Wireless Networks: Protocols and Systems", Prentice Hall PTR. 2002: 55-77

[6] Zygmunt J. Haas Marc R.Pearlman and Prince Samar, "The Zone Routing Protocol for Adhoc Networks", draft-ietfmanet-zone-zrp-04.txt, July 2002.

[7] Perkins CE, Ad Hoc Networking[M]. London: AddisonWesley, 2001

[8] Ding Junxia and Ningbo, Simulation and evaluation of the performance of FSR Routing Protocols based on Group Mobility Model in Mobile Ad Hoc, 2001 IEEE.

[9] Azzedine Boukerche, A Performance Comparison of Routing Protocols for Ad Hoc Networks, 2001 IEEE.

[10] Haas, Zygmunt J., Pearlman, Marc R.: The Performance of Query Control Schemes for the Zone Routing Protocol, August 2001, IEEE/ACM Transactions on Networking, Vol. 9, No. 4

[11] G. Pei, M. Gerla, and T. W. Chen, "Fisheye State Routing in Mobile AdHoc Networks," In Proceedings of the 2000 ICDCS workshops, Taipei, Taiwan, Apr. 2000.

[12] Subramanya Bhat.M, Shwetha.D, Devaraju.J.T," A Performance Study of Proactive, Reactive and Hybrid Routing Protocols using Qualnet Simulator" International Journal of Computer Applications (0975 - 8887) Volume 28- No.5, August 2011

[13] The Qualnet simulator www.scalable-networks.com
[14] E. M. Royer and C. Toh, "A Review of Current Routing Protocols for Ad Hoc Mobile Wireless Networks," IEEE Personal Communications, pp. 46-55, April 1999.

[15] C. E. Perkins and P. Bhagwat, "Highly Dynamic DestinationSequenced Distance-Vector Routing (DSDV) for Mobile Computers," SIGCOMM, London, UK, August 1994, pp. 234-244.

[16]Charles Perkins, Elizabeth Royer, and Samir Das. "Ad hoc on demand distance vector (AODV) routing", IETF RFC No. 3561, July 2003.

[17] Parma Nand, S.C. Sharma, Rani Astya, "Traffic Load based Performance Analysis of DSR, STAR \& AODV Adhoc Routing Protocol", International Journal of Advanced Computer Science and Applications, vol 1 No 4, pp 58-62.

[18] M.Benzaid, P.Minet,K.A.Agha, Inegrating fast mobility in the OLSR routing protocol, INRIA research reports, June 2002.

[19] Takashi Hamma,Takashi Katoh,Bhed Bahadur Bista,An Efficient ZHLS routing protocol for mobile ad hoc networks,Proceedings of the 17th International Conference on Database and Expert Systems Applications(DEXA' 06), 2006,IEEE.

[20] Raghupathy Sivakumar, Prasun Sinha,Vaduvur Bharghavan, CEDAR: A Core-Extraction Distributed Ad Hoc Routing Algorithm, IEEE Journal on Selected Areas in Communications, August 1999.

\section{AUTHORS PROFILE}

Sumaiya Thaseen $\mathbf{I}$ is currently pursuing her $\mathrm{Ph} . \mathrm{D}$ degree in School of Information Technology and Engineering from VIT University, Vellore, India. A life member of Computer Society of India (CSI). Her area of interests are mobile ad hoc networks and network security.She is working as an assistant professor in VIT University, Vellore for the past five years.

K. Santhi is currently pursuing her Ph.D degree in School of Information Technology and Engineering from VIT University, Vellore, India. A life member of Computer Society of India (CSI). Her area of interests are sensor networks and network security. She is working as an assistant professor in VIT University, Vellore for the past five years. 